\title{
Use of Native Potatoes for Research and Breeding
}

\author{
John Bamberg ${ }^{1}$ and Alfonso del Rio \\ US Potato Genebank, USDA/Agricultural Research Service, 4312 Highway 42, Sturgeon Bay, WI 54235
}

Additional index words. germplasm, collecting, stoloniferum

\begin{abstract}
Potato is an important world crop with an abundant diversity of wild relatives for research and breeding. Over 100 tuber-bearing Solanum relatives of the cultivated potato occur naturally from southern Chile to the southwest United States. Only five of these have been reported in the United States, and only two exist with certainty (S. stoloniferum/fendleri and $S$. jamesii). The authors and colleagues have conducted expeditions in the southwest United States each season since 1992, collecting over 200 new germplasm samples. This work has greatly improved the representation of these species in the genebank with respect to geography and genetic diversity available to germplasm users worldwide. Corrected or refined collection site information now makes it possible to easily find these typically small populations for continued in situ study and sampling. Collecting experiences, often in contrast with conventional wisdom, have been documented for the benefit of future collectors. A broader sampling of the region has allowed studies of the association of eco-geo parameters with patterns of genetic diversity in an attempt to predict "hot spots" of diversity for future expeditions. Evaluation of these materials has resulted in the discovery of new useful traits-novel mutants, disease and pest resistances, and human nutritional compounds.
\end{abstract}

Potatoes are native to the Americas, concentrated in the western mountains extending from southern Chile to southern Utah and Colorado in the United States. The authors here describe their efforts to collect and study populations of the two wild species originating in the United States. The diploid, Solanum jamesii, is assumed to be an obligate outcrosser and is very heterozygous and heterogeneous. This is the most northern of all the potatoes. In fact, nearly all of the known populations of this species originate in the United States. The tetraploid, historically known as Solanum fendleri, and referred to as such here, has recently been reclassified under Solanum stoloniferum, a species name that now includes four of the five species originally described under series Longipedicellata and also distributed throughout Mexico (Spooner et al., 2004). As expected of a disomic polyploid, plants of this species produce abundant spontaneous seed from selfing and have been shown by DNA markers to be very homogeneous within populations (Bamberg and del Rio, 2004). Both of these species allow the opportunity to sample natural populations clonally (as tubers) or as botanical seeds.

\section{COLLECTING QUESTIONS OF INTEREST TO THE GENEBANK}

In 1992, the first of annual expeditions was organized by the Association of Intergenebank Collaborators, an international consortium of potato genebank curators (Bamberg, 1992; Bamberg et al., 1995). Like with all expeditions, this trip sought to collect and preserve new germplasm to be maintained in the genebanks for breeding. However, this initial

\footnotetext{
Received for publication 9 Mar. 2011. Accepted for publication 25 Mar. 2011.

This paper was part of the workshop "Horticultural Value of Wild Genetic Resources" held 3 Aug. 2010 at the ASHS Conference, Palm Desert, CA, and sponsored by the Genetics and Germplasm (GG) Working Group.

${ }^{1}$ To whom reprint requests should be addressed; e-mail John.Bamberg@ars.usda.gov.
}

expedition also sought specifically to recollect samples from sites originally collected in 1958 and 1978. Thus, these materials would also serve to answer a collecting research question: Are populations in the genebank, sometimes collected decades earlier, still genetically representative of the corresponding plants living in the wild? We found that they were not (del Rio et al., 1997). Thus, we gained insights about the status of old collections and recollections: Although it is a negative to find that the old collections cannot be assumed to be backed up in nature, it is positive to find that the provenance data are a handy guide to the location of sites from which new diversity can be collected.

Germplasm managers would like to know if stocks from the wild seem to have new genetic diversity only because they are in some way subjected to selection in the genebank that "domesticates" them. We found that this was not the case (del Rio and Bamberg, 2003). For example, plants of $S$. jamesii collected in the wild may appear to be uniform for dominant markers, but they do possess the recessive alleles that become evident when the accession is converted to botanical seeds in the genebank. So the same genetics are present in both locations, if not the same phenotypes. This observation also illustrates that traits noted in genebank-derived seedlots may not be present in the wild.

Indeed, one of the most important findings of our work relevant to collecting is that there was usually no correspondence between ecogeographic patterns and genetic relatedness of populations (del Rio et al., 2001). It is typically regarded as common sense that one should collect from a diversity of habitats and dispersed locations to broaden the sampling for genetic diversity. However, the evidence indicates that one should simply collect many populations and assess their diversity empirically.

We also conducted a case study to determine if a different genetic sample would be recovered by collecting tubers versus seeds. This was found to be true for the tetraploid S. fendleri. Apparently, it may exist as a population of mixed inbreds from which only some genotypes present seeds at the time of collection (Bamberg et al., 2009).

In recent years, collecting has focused on the sky islands of southeastern Arizona. These mountain ranges can have two types of collection sites: those very easily accessible by car ("easy") and those only accessible by extensive trail hiking and camping ("remote" = the crests and peaks). We found that although these sites may have only a few miles of spatial separation, the genetics at "remote" sites may be very different and therefore warrant the effort to collect there (Bamberg et al., 2010).

\section{THE DIVERSITY OF U.S. STOLONIFERUM}

The lumping of all $S$. fendleri under the species name stoloniferum highlights the question of how our collections of the U.S. origin relate to their new Mexican counterparts. Clustering of coded representatives of over 400 populations showed that certain types could be consistently grouped. The populations originating in the United States never clustered with those having finer leaflets and tall unbranched black stems (previously classified as stoloniferum) or those lighter green, very hairy, white-flowered populations with relatively unbranched tall stems (previously classified as polytrichon). In particular, those of U.S. origin never have white flowers.

\section{COLLECTING TIPS}

In 2003, we published an article (Bamberg et al., 2003) summarizing the results of several experiments on the topic of collecting methods and also documenting a decade of our experiences in the field. We hoped this would be particularly valuable to subsequent collectors, because what we encountered often greatly varied from expectations. For example, the complete absence of reports for 100 years in a certain area, and doubtful responses from experienced local botanists does not mean robust populations do not exist there. Similarly, the supposed ideal time of collection, expected appearance of the plants, and likely habitats are also often misleadingly 
idealized when the truth is that these are so variable as to be predicable only within limits of a few fundamental parameters (e.g., potatoes are almost never found where it is always very dry or below 5000 feet elevation).

\section{USEFUL TRAIT DISCOVERY}

This work has not only provided better representation of the species, and insights into collecting techniques and the status and dynamics of genetic diversity, but has also captured germplasm with several novel traits of interest to the potato industry. These include nematode resistance (Brown et al., 2004), extremely high antioxidants (Hale et al., 2008; Nzaramba et al., 2007), extreme tuber dormancy (Bamberg, 2010), antiprostate cancer effects (Nzaramba et al., 2009), and low tuber pH (Kiszonas and Bamberg, 2010).

\section{CONCLUSIONS}

Like all genebank-related work, the efforts described here have the goal of providing germplasm users with the best possible resource for breeding and basic study, which supports the ultimate goal of producing a crop that can better meet the nutritional needs of the public. A mechanic works most efficiently with a broad diversity of tools that he knows how to use and that are properly organized and maintained. Similarly, genebanks need to provide breeders with the broadest possible diversity of germplasm that is well character- ized, documented, and with supporting technology to deploy it.

\section{Literature Cited}

Bamberg, J., Z. Huaman, and R. Hoekstra. 1995. International cooperation in potato germplasm. In: International germplasm transfer: Past and present, p. 177-182. In: Duncan, R. (ed.). CSSA Special Publication \#23. CSSA/ASA/ SSSA, Madison, WI.

Bamberg, J.B. 1992. World potato genebank collaborators meet at Braunschweig. Diversity 8:22.

Bamberg, J.B. 2010. Tuber dormancy lasting eight years in the wild potato Solanum jamesii. Amer. J. Potato Res. 87:226-228.

Bamberg, J.B. and A.H. del Rio. 2004. Genetic heterogeneity estimated by RAPD polymorphism of four tuber-bearing potato species differing by breeding system. Amer. J. Potato Res. 81:377-383.

Bamberg, J.B., A.H. del Rio, C.F. Fernandez, A Salas, S. Vega, C. Zorilla, W. Roca, and D. Tay. 2010. Comparison of 'remote' versus 'easy' in situ collection locations for USA wild Solanum (potato) germplasm. Amer. J. Potato Res. 87: 277-284.

Bamberg, J.B., A.H. del Rio, Z. Huaman, S. Vega, M. Martin, A. Salas, J. Pavek, S. Kiru, C. Fernandez, and D.M. Spooner. 2003. A decade of collecting and research on wild potatoes of the southwest USA. Amer. J. Potato Res. 80:159-172.

Bamberg, JB, AH del Rio, and R. Moreyra. 2009. Genetic consequences of clonal versus seed sampling in model populations of two wild potato species indigenous to the USA. Amer. J. Potato Res. 86:367-372.

Brown, C.R., H. Mojtahedi, and J.B. Bamberg. 2004. Evaluation of Solanum fendleri as a source of resistance to Meloidogyne chitwoodi. Amer. J. Potato Res. 81:415-419.

del Rio, A.H. and J.B. Bamberg. 2003. The effect of genebank seed increase on the genetics of recently collected potato (Solanum) germplasm. Amer. J. Potato Res. 80:215-218.

del Rio, A.H., J.B. Bamberg, Z. Huaman, A. Salas, and S.E. Vega. 1997. Assessing changes in the genetic diversity of potato genebanks. 2. In situ vs ex situ. Theor. Appl. Genet. 95:199-204.

del Rio, A.H., J.B. Bamberg, Z. Huaman, A. Salas, and S.E. Vega. 2001. Association of eco-geographical variables and genetic variation in native wild US potato populations determined by RAPD markers. Crop Sci. 41:870-878.

Hale, A.L., L. Reddivari, M.N. Nzaramba, J.B. Bamberg, and J.C. Miller, Jr. 2008. Interspecific variability for antioxidant activity and phenolic content among Solanum species. Amer. J. Potato Res. 85:332-341.

Kiszonas, A.M. and J.B. Bamberg. 2010. Survey of tuber $\mathrm{pH}$ variation in potato (Solanum) species. Amer. J. Potato Res. 87:167-176.

Nzaramba, M. Ndambe, J.B. Bamberg, and J.C. Miller, Jr. 2007. Effect of propagule type and growing environment on antioxidant activity and total phenolic content in potato germplasm. Amer. J. Potato Res. 84:323-330.

Nzaramba, M. Ndambe, L. Reddivari, J.B. Bamberg, and J.C. Miller, Jr. 2009. Antiproliferative activity and cytotoxicity of Solanum jamesii tuber extracts on human colon and prostate cancer cells in vitro. J. Agr. Food Chem. 57:8308-8315.

Spooner, D.M., R.G. van den Berg, A. Rodríguez, J. Bamberg, R.J. Hijmans, and S.I. Lara-Cabrera. 2004. Wild potatoes (Solanum section Petota) of North and Central America. Syst. Bot. Monogr. Vol. 68. The American Society of Plant Taxonomists, Ann Arbor, MI. 